\title{
Ideias e formação de agenda de uma reforma educacional
}

\author{
Carlos Vasconcelos Rocha*
}

\section{Resumo}

Este trabalho busca demonstrar como a relação entre ideias, atores, instituições e interesses explicam a formação da agenda da reforma do sistema público de ensino de Minas Gerais das últimas décadas do século passado. Atores diversos em termos de ideologia e interesses compartilham um mesmo paradigma de reforma educacional, segundo os valores de descentralização e participação. Apesar disso, desenvolvem argumentos diferenciados.

Palavras-chave: Politicas públicas. Conhecimento. Formulação de políticas educacionais.

\section{Ideas in the making of an educational reform agenda Abstract}

This article aims to demonstrate how the relationship among different ideas, actors, institutions and interests explain the policy making processes of the reform of the State public school system in Minas Gerais, Brazil in the last decades of the last century. The different actors, presenting distinct political perspectives, interests and ideologies shared one common policy paradigm: decentralization and participation. However, they developed different arguments. Keywords: Public policy. Knowledge. Educational policy-making.

\section{Ideas y Formación de agenda de una reforma educacional Resumen}

Este trabajo tiene por objeto demostrar como la relación entre ideas, actores, instituciones e intereses explican la formación de la agenda de la reforma del sistema público de enseñanza de Minas Gerais (Provincia de Brasil) de las últimas décadas del

* Doutor em Ciências Sociais, Universidade Estadual de Campinas (Unicamp), SP; Professor e Pesquisador, Curso de Pós-Graduação em Ciências Sociais, Pontifícia Universidade Católica de Minas Gerais (PUC-Minas). E-mail: carocha@pucminas.br 
siglo pasado. Distintos actores, en términos de ideología e intereses, comparten un mismo paradigma de reforma educacional, según los valores de descentralización y participación. A pesar de ello, desarrollan argumentos diferenciados.

Palabras claves: Políticas públicas. Conocimiento. Formulación de políticas educacionales.

No contexto do esforço de se repensar o desenho das instituições estatais, o tema da reforma de sistemas educacionais esteve presente na agenda de diversos países do mundo a partir do início dos anos de 1980. Na América Latina, por exemplo, foram introduzidas importantes mudanças nesses sistemas em pelo menos vinte paises. No Brasil não foi diferente. A reforma das instituições educacionais ocupou lugar de destaque no contexto geral da reforma do Estado. No entanto, sendo o Brasil um país federal em que as prerrogativas sobre a produção de politicas públicas são distribuídas entre diferentes esferas de governo, o processo de reforma educacional apresentou caracteristicas especificas.

A estruturação da educação pública brasileira organiza-se, especialmente no nivel fundamental, através de redes estaduais e municipais de ensino. Dada esta fragmentação da estrutura de oferta, típica dos sistemas federativos, as experiências de redefinição das instituições públicas de educação foram diversificadas segundo as diferentes condições politicas, financeiras e administrativas de cada governo subnacional (ALMEIDA, 1995). Em que pese essas diferenças, a concepção geral que orientou a discussão das reformas, no caso brasileiro, foi descentralizar o sistema, seja no sentido da sua municipalização, seja repassando a responsabilidade da gestão das escolas para os professores, funcionários, pais e alunos, através da articulação de espaços de participação e representação.

Esta ênfase na descentralização e na participação como pilares das reformas educacionais configurou um consenso abarcando atores diferenciados. A existência de propostas de reforma a partir de objetivos compartilhados por grupos dispares em termos de interesses e ideologias, coloca em relevo uma perspectiva que foi negligenciada pela ciência política durante muito tempo: a relação entre ideias, atores, instituições e interesses na produção de políticas públicas. Este trabalho busca explorar essas relações em referência à reforma do sistema público de ensino de Minas Gerais das últimas décadas do século passado. Essa reforma resultou, em certa medida, de um deslocamento considerável em termos de grupos no poder: com a consolidação do regime democrático, grupos que se opuseram ao regime autoritário passaram a ocupar espaços de poder no Estado. Como a transição para a democracia foi negociada entre políticos remanescentes do regime autoritário e uma oposição que se afirmava como alternativa de poder, a configuração das elites governantes na democracia instaurada era heterogênea. Antigos atores autoritários reciclaram suas posições, no sentido do abandono da defesa de um autoritarismo centralizador, para manterem-se no poder. 
Assim, são os novos atores que se opuseram ao autoritarismo, ao lado de antigos atores com concepções recicladas, que estabeleceram um novo paradigma para a estruturação do sistema público educacional mineiro, segundo os requisitos fornecidos por dois processos que se sobrepõem: a democratização e a globalização. Para o caso da educação pública mineira, se o contexto que marcou as mudanças na primeira metade da década de 1980 foi o movimento pela democratização ocorrido no Brasil, na Reforma Educacional de 1991, o chamado processo de globalização agregou elementos que incentivaram as reformas institucionais. 0 curioso é que a transformação do sistema público de educação, segundo os valores de descentralização e participação, foi conduzida, em momentos diferentes, por grupos ideologicamente diferenciados e com interesses contrapostos, com cada qual elaborando um corpo de ideias específicas. No primeiro momento, setores de esquerda conectados com movimentos sociais, passaram a implementar um conjunto de ideias baseadas em teorias de classes sociais, comprometidas com a democracia e com politicas redistributivas. No segundo momento, elites desenvolvimentistas e agências internacionais de financiamento ao desenvolvimento, como o Banco Mundial, enfatizaram a necessidade de qualificar a força de trabalho segundo os requisitos tecnológicos das novas formas de produzir, criando, portanto, as condições para a reprodução de capital.

Este trabalho busca argumentar que, apesar dessas diferenças, um grande consenso foi criado entre os dois grupos em torno da importância e do valor da educação, seja como instrumento de desenvolvimento econômico e social, seja como instrumento da formação politica e cultural do cidadão. A defesa da educação passou a ser feita tanto pelos adeptos da economia de mercado como pelos setores que analisavam a sociedade em termos de classes sociais. Ambos, no entanto, compartilharam da ideia de que a reforma deveria se basear nos principios da descentralização e participação.

Iniciaremos o trabalho com uma breve referência teórica à relação entre ideias, interesses e produção de políticas públicas. Posteriormente, buscaremos abordar os dois momentos que demarcam a formulação e implementação da reforma do sistema de educação de Minas Gerais. Enfatizaremos o contexto geral, os atores e as ideias envolvidas nos esforços reformistas em cada um dos momentos. E finalmente, em sua última parte, tentaremos esboçar uma reflexão sobre o papel explicativo que as ideias, os atores e seus interesses tiveram no caso aqui tratado.

\section{Uma breve nota teórica: ideias e políticas públicas}

Durante muito tempo, na análise de políticas públicas, as ideias aparecem, reiteradamente, como epifenômenos de fatores causais subjacentes. Em certas perspectivas teóricas bastante difundidas, elas aparecem como mero rebatimento de interesses de classes ou de grupos de interesses. Com o redirecionamento do foco da teoria política para as instituições que o neoinstitucionalismo procede a partir de meados da década de 80 , a dimensão das ideias ganha centralidade analítica no 
estudo das políticas públicas. A forma como essa dimensão é incorporada no desenvolvimento das teorias sobre essa área de estudo é bastante diferenciada, envolvendo autores e proposições diversificadas. Não é o caso, aqui, de fazer um inventário desse debate. ${ }^{1}$ Nosso objetivo é apenas apresentar, de forma resumida, algumas proposições teóricas que auxiliem a análise do caso de reforma aqui tratado.

Em desenvolvimento teórico recente, mas com resultados consideráveis em termos de pesquisas, diversos autores buscam explicar a produção de políticas públicas a partir da concepção de uma rede de atores que se articulam para atuar numa área política especifica, segundo interesses e ideias compartilhados (policy advocacy coalition). Essa rede de atores expressa um acordo de ideias sobre a definição e a solução de determinados problemas públicos. No caso das políticas educacionais, talvez por ser uma área com grande presença de atores com considerável capacidade de teorização, ganha relevo o que foi denominado de "comunidades epistêmicas", ou seja, uma rede de especialistas em uma determinada área de políticas que transmite e mantém crenças sobre a veracidade e aplicabilidade de formas particulares de conhecimento (HAAS, 1992). Nesse sentido, é importante ressaltar que a habilidade em expor ideias tem um papel relevante na política, em geral, e, especificamente, na produção de políticas públicas. Membros de uma policy advocacy coalition, em um setor de politica pública especifico, compartilham valores e formas de conhecimento sobre como solucionar problemas que os distinguem de outros grupos com os quais competem (SABATIER; JENKINS-SMITH, 1993).

Uma percepção que ganha tratamento diferenciado no estudo de políticas públicas, nessa perspectiva das ideias, é a de que as políticas públicas surgem como resultado do aprendizado com políticas anteriores (HALL, 1993; ROSE, 1993). As ideias não surgem do nada, pois os atores avaliam experiências negativas ou positivas das políticas passadas e buscam aplicar as lições ao seu contexto. 0 desdobramento dessa afirmação não é tão simples. Hall (1993), por exemplo, afirma que o processo de aprendizado com as políticas anteriores (policy learning) pode tomar várias formas, dependendo do tipo de mudança envolvido. Ele propõe a existência de três tipos distintos de mudanças nas políticas, cujos efeitos sobre o papel das ideias são diferenciados. Segundo Hall, as mudanças de primeira e segunda ordem são limitadas, já que compostas por ajustes rotineiros em políticas em andamento ou por alteração de instrumentos para alcançar a mesma hierarquia de metas traçadas anteriormente. Com relação às essas duas ordens de mudanças, a ação estatal é consideravelmente insulada das pressões pluralistas do sistema político, e as mudanças ocorrem de forma incremental, derivadas, em grande medida, do aprendizado de técnicos e burocratas com as experiências passadas. A mudança de terceira ordem, no entanto, é mais profunda, pois envolve tanto a modificação dos instrumentos de políticas, quanto das metas e do próprio sistema de ideias e padrões que

1 Para tal, ver, por exemplo, Faria (2003) e John (1999). 
orientam os especialistas no exame de problemas. Segundo Hall, há aí uma mudança de paradigma nos termos propostos por T. Kuhn (1975)².

Na mudança de paradigma, o processo é impulsionado por fatores sociais e quase nunca por fatores estritamente científicos. A mudança é configurada pelo embate dos interesses em jogo. Quando um grupo no poder não consegue solucionar os problemas com os quais se defronta, a partir de um determinado paradigma, sua continuidade de mando torna-se ameaçada. Novas ideias, geralmente sustentadas por atores políticos alternativos, são necessárias para a resolução dos problemas. No caso, um novo paradigma orienta a mudança das instituições, acompanhado de um reequacionamento da estrutura de poder que extrapola os limites do Estado, envolvendo políticos, partidos políticos, grupos de interesse e imprensa, que disputam o poder através do embate de ideias.

Colocada a questão nestes termos, emerge outro aspecto que envolve uma intrincada polêmica entre diversos autores e que diz respeito à relação entre ideias e interesses. Sem aprofundar essa discussão, é plausivel considerar que os atores geralmente cuidam de defender seus interesses ao polemizarem no campo das ideias. Dessa forma, as ideias cumprem um duplo papel na elaboração das políticas públicas: fornecem uma direção de ação na resolução de problemas, na mesma medida em que legitimam alguns interesses em detrimento de outros. 0 próprio Hall defende que não é necessário estabelecer uma rígida distinção entre politics as social learning e politics as a struggle for power (HALL, 1993, p. 292).

Este trabalho trata de uma reforma que envolve uma mudança de paradigma, relacionada, portanto, com mudanças sociais e políticas, com o esgotamento de um conjunto de ideias sobre políticas educacionais e com o consenso entre atores diversos sobre novos fundamentos de reforma institucional. Cremos ser necessário definir claramente a apropriação que fazemos dessa ideia de paradigma proposta por Hall (1993). 0 argumento sustentado aqui é o de que grupos ideologicamente diferenciados, um mais à esquerda e outro de centro-direita, compartilham uma proposta de estruturação institucional comum para a reforma do sistema público de ensino de Minas Gerais, baseada nos princípios da descentralização e participação. Assim, se ambos os grupos compartilham um paradigma no sentido de concordarem sobre os princípios que deveriam fundamentar o desenho das instituições do setor, se diferenciam nos valores e nos objetivos finais almejados, bem como nos argumentos utilizados para sustentar suas posições. Os grupos à esquerda, como veremos adiante, enfatizam a descentralização como forma de aprofundar a participação democrática e alcançar uma maior igualdade

2 Kuhn (1975) afirma que em cada momento do desenvolvimento das ciências há um conjunto de pressupostos e crenças que são compartilhadas pelos cientistas na definição dos problemas da investigação e na elaboração das teorias propostas para solucioná-los. Este quadro mental é provisório, no sentido de que quando os problemas internos a um paradigma são excessivos, coloca-se em dúvida a própria validade do paradigma adotado, implicando em sua substituição por outro. 
na distribuição da riqueza material de uma sociedade tão desigual como a brasileira; os grupos à direita visam a lograr maior eficiência no sistema educacional, requisito para adequar as habilidades dos trabalhadores aos requisitos do sistema produtivo do mundo globalizado. Essa afinidade entre grupos ideologicamente distintos sobre o desenho da reforma - e vale ressaltar aqui que o acordo sobre a estrutura institucional adequada tem desdobramentos concretos, já que agrega forças no sentido de implementar ações bastante concretas ${ }^{3}$;- é algo que foi expresso por Tendler (1999, p. 44):

0 pensamento [...] sobre a reforma do setor público e descentralização mistura argumentos [...] Embora estas correntes de pensamento sejam, em vários sentidos, muito distintas, no mundo político elas convergem para um conjunto de asserções e suposições implícitas que surgem regularmente em milhares de reuniões, apresentações de projeto e textos de doadores sobre como melhorar o governo. Por prezar a concisão, [...] refiro-me a ela como 'descentralização e participação'.

\section{A reforma educacional em Minas Gerais: atores, ideias e instituições}

A reforma do sistema público de ensino de Minas Gerais, formulada e implementada no contexto do movimento mais amplo da reforma do Estado brasileiro iniciada nos anos de 1980, pode ser dividida em dois momentos, explicados por dois processos bem mais amplos. Denominaremos estes dois momentos como Reforma do Partido Democrático Brasileiro (PMDB) ${ }^{4}$ (1983-1986), referente ao período de governo de Tancredo Neves e conduzida por setores de esquerda do partido, e Reforma de 1991 (cujas principais medidas são tomadas até 1992), realizada no contexto do governo Hélio Garcia e liderada por um grupo de centro-direita. Estes dois momentos são intermediados pelo governo Newton Cardoso (1987-1990), que reforça as práticas centralizadas e clientelistas, que são antitéticas aos objetivos do esforço reformista. Trataremos, portanto, de uma reforma que, apesar de segmentada no tempo, apresenta uma coerência de propósitos ao longo de sua consecução, e que tem como protagonistas, nos dois momentos distintos, grupos ideologicamente diversos. ${ }^{5}$

3 Esse acordo sobre um mesmo arranjo institucional por grupos com objetivos diversos é possível pela imprevisibilidade dos efeitos de certas escolhas institucionais: dado o caráter inerentemente caótico das interações sociais, ninguém pode garantir quais efeitos terão certas decisões. Sobre isso ver, por exemplo, Santos (1987).

40 PMDB é um partido político que aglutinou os grupos de oposição ao regime militar no Brasil. Reuniu grupos ideologicamente diversos na luta contra o autoritarismo. A reforma da educação de Minas Gerais foi conduzida por uma ala da esquerda do partido.

5 Essa periodização da reforma pode provocar certa confusão. No primeiro período analisado, o governador Tancredo Neves foi substituído no decorrer do seu mandato pelo seu vice, justamente Hélio Garcia, governador no segundo período analisado. Mais que as características individuais de ambos os governadores, as coalizões de governo explicariam as diferenças ideológicas que envolveram as ações reformistas em ambos os períodos. Diferenças que são claramente contrastantes se considerarmos efetivamente os grupos que dirigiram a Secretaria Estadual de Educação, representados por Neidson Rodrigues, no primeiro caso, e Mares Guia Neto, no segundo. 
Se a reforma se relaciona com concepções ideológicas díspares, em cada uma de suas etapas a agenda política enfatiza aspectos diferenciados. Num primeiro momento, ao longo da década de 1980, a grande questão que ocupa o centro da política brasileira é a luta contra o regime militar e as demandas pela democratização política do país. Posteriormente, no início dos anos de 1990, desalojados os militares do poder e estabelecida a base jurídico-constitucional da democracia política, outra ordem de eventos ganha preponderância como referência para o embate político nacional. Sem substituir, mas sobrepondo-se à agenda da democratização, a chamada globalização, especialmente através dos seus impactos no mundo da produção e do trabalho, passa a fornecer novos elementos explicativos para os processos políticos que ocorrem no Brasil. São essas referências contextuais que situam os atores e suas ideias no processo de mudança institucional considerado neste trabalho. Tentaremos, assim, abordar os dois momentos da reforma educacional mineira, enfocando, em cada um deles, as ideias que pautaram a ação dos grupos envolvidos, seus interesses e o contexto na qual foram gestadas.

\section{A Reforma no contexto da democratização}

A descentralização do ensino público de Minas Gerais, que se iniciou nos anos 80, não foi um fato isolado. Foi parte de um processo de redefinição do desenho das instituições estatais brasileiras, que resultou do esgotamento das formas de exercício do poder características do regime autoritário iniciado em 1964. Dai até 0 início dos anos 80, o Estado brasileiro ficou sob controle de forças avessas aos direitos civis e políticos básicos dos cidadãos, sendo sua relação com a sociedade marcada pela repressão. 0 exercício do poder político era caracterizado pela centralização políticoadministrativa e pelo autoritarismo.

Como reação a esse estado de coisas, pode-se considerar como um marco para a implementação da reforma das instituições educacionais públicas brasileiras a eleição por sufrágio universal para os governos estaduais, em 1982, depois de um longo período em que os governadores eram indicados indiretamente pelos militares e seus aliados no poder. Em certo sentido, o que ocorreu nessa eleição foi uma manifestação da maioria do eleitorado em favor de mudanças, ao eleger, nos principais estados da federação, governadores comprometidos com os ideais democráticos. Especificamente em Minas Gerais, foi eleito como governador Tancredo Neves, do PMDB, partido que aglutinou diversos grupos políticos em oposição ao regime militar. Dessa forma, o partido assumiu o governo do estado com o intuito de realizar mudanças na política, na economia e nos critérios e métodos de gestão dos recursos públicos como, em geral, todos os governos estaduais de oposição do pais que estavam tomando posse naquele momento ${ }^{6}$. Na formação do novo gover-

6 Além de Minas Gerais, por exemplo, em São Paulo e Rio de Janeiro assumem os governos estaduais opositores históricos do regime autoritário, respectivamente, Franco Montoro e Leonel Brizola. 
no mineiro, a Secretaria de Estado da Educação (SEE) passou a ser dirigida por um grupo da ala esquerda do PMDB, denominado de "autênticos", que imprimiu nova orientação para a política educacional do estado. As concepções políticas de esquerda dos novos gestores da educação orientaram as ações na área. Esta primeira fase, que vai de 1982 a 1987, foi marcada pelo primeiro grande movimento de reforma do ensino público estadual no período de democratização política do país.

Como ressaltamos anteriormente, o contexto nacional forneceu o elemento motivador da reforma do sistema educacional no estado: a construção da democracia. Em sua dimensão educacional, esse objetivo envolvia a busca da melhoria da qualidade de ensino e a democratização das escolas, o combate aos problemas da evasão escolar e das altas taxas de repetência, a capacitação de pessoal e reformulação de conteúdos e currículos. Especificamente, mudanças na gestão escolar no sentido de democratizá-la, através da criação de espaços de participação de professores, funcionários, pais e alunos nos processos de tomada de decisões foram muito comuns nos estados e municípios brasileiros (ALMEIDA, 1995).

Assim, com o processo de abertura política e particularmente com a vitória dos partidos de oposição nas eleições proporcionais e majoritárias de 1982, principalmente nos estados mais industrializados, inaugurou-se um processo de redirecionamento das políticas sociais no Brasil. No caso da educação em Minas Gerais, a mudança se orientou, desde o início, pela busca da democratização e autonomia da gestão das escolas. Concretamente, o objetivo central da reforma no estado era a descentralização do sistema educacional como forma de propiciar a participação dos setores envolvidos com a educação pública na sua gestão. 0 grupo dirigente da SEE tinha ideias claras do que fazer, derivadas de uma leitura de corte marxista da realidade social, cristalizada em percepções que vinham sendo gestadas, desde 0 final dos anos de 1970, por amplos setores da sociedade civil.

Essa ênfase participativa dos novos dirigentes da educação sustentou a própria definição do programa de reforma, cujo momento principal foi a realização do I Congresso Mineiro de Educação, proposto pelo governo estadual e realizado de 4 de agosto a 7 de outubro de 1983. 0 I Congresso foi um fórum de discussão com 0 objetivo de definir princípios para a reforma do sistema público de educação. Envolveu amplos setores governamentais e da sociedade civil, como associações de servidores, universidades, sindicatos e representantes de movimentos sociais diversos, dentre outros. A origem do I Congresso está nessa advocaty coalition, composta por atores diversos que compartilham a crença na democratização politica e na reversão dos princípios que organizavam o sistema educacional vigente até então. Na verdade, o I Congresso representou o eco das reivindicações da sociedade civil no governo, já que o grupo dirigente da SEE era oriundo de movimentos sociais que se opuseram ao regime autoritário. 
A concepção geral da reforma resultou, portanto, do projeto desenvolvido pela equipe de intelectuais que se ocupou das questões educacionais do governo estadual, em amplo diálogo com parcelas da sociedade civil, especialmente por ocasião da realização do I Congresso Mineiro de Educação. Relevante também foi o papel de setores da própria burocracia do sistema estadual de educação, cujas propostas e articulações junto a setores da sociedade civil influenciaram e sustentaram o esforço reformista. 0 fato é que diversos funcionários estaduais da área de educação se engajaram em movimentos que defendiam a reforma. Além de participar ativamente do I Congresso Mineiro de Educação, essa burocracia foi recrutada para os cargos de direção na SEE, até então, ocupados, em geral, por prepostos de políticos governistas, cujo objetivo central era instrumentalizar as instituições públicas educacionais visando angariar apoios políticoeleitorais para seus grupos políticos. Resultado da participação de diversos atores, as propostas elaboradas no I Congresso vão orientar a elaboração do Plano Mineiro de Educação 1984-1987 (MINAS GERAIS, 1984a). Coerente com a linha adotada até então, a política setorial de educação, contemplada no Plano, foi concebida como meio de estabelecer a

justiça social, através da formulação de uma mudança embasada no processo de democratização entendido como o comprometimento do indivíduo consigo mesmo e com a sociedade, o que deverá conduzir o homem ao exercício pleno da liberdade e à participação efetiva nos processos decisórios da vida cultural, econômica, política e social (MINAS GERAIS, 1984a, p. 3).

Conforme exposto no documento, os princípios orientadores da política educacional visavam a universalização do ensino, a melhoria de sua qualidade e ao respeito aos valores de cada localidade. Além disso, argumentava-se, como crítica à concepção adotada até então, que antes de preparar as classes subalternas para sua maior eficiência na organização do trabalho, a educação deveria fornecer elementos interpretativos do mundo concreto, com o objetivo de transformá-lo. Conforme fica explícito nas palavras abaixo, cristalinas na expressão do papel classista que a educação deveria cumprir, deve-se

priorizar os alunos das camadas populares da sociedade, no sentido de instrumentalizar e implementar a sua luta de classe bem como a compreensão dos mecanismos de dominação que são usados pela classe dominante contra a classe dominada (MINAS GERAIS, 1984b, p. 2).

Para tal, o Plano propõe a participação da sociedade na definição dos rumos da política educacional, o que pressupõe a descentralização políticoadministrativa, "através do fortalecimento dos órgãos regionais e a criação de outras 
instâncias ao nivel do município e da escola na discussão, elaboração, execução e acompanhamento das atividades educacionais" (MINAS GERAIS, 1984a, p. 20). A meta almejada, relatada no documento, é o envolvimento das pessoas em todo o processo de produção das políticas educacionais, assegurando a apropriação dos planos educacionais pelas populações às quais se destinam. Potencializar a capacidade participativa da comunidade nos assuntos educacionais implicaria em fortalecer o próprio regime democrático.

Com base nessas ideias, foi formulada uma série de objetivos que apontavam para a descentralização do sistema. Especificamente, entre diversas outras propostas, vale ressaltar as seguintes:

descentralização administrativa e pedagógica no processo de decisão e execução, confiando maiores e mais complexas responsabilidades aos órgãos regionais; institucionalização de mecanismos aptos a gerar mais intensa e efetiva participação, não só dos agentes do Estado mas de toda a comunidade, nos diferentes níveis em que se desdobra a atuação do sistema; planejamento descentralizado na tentativa de recuperar a influência das bases, tanto na linha de criação e condução de programas, quanto na linha de controle e avaliação; maior autonomia das escolas e melhoria de suas condições de trabalho (materiais, humanas, culturais e administrativas) de forma a estimular e garantir a qualidade da educação a ser realizada na escola; estabelecimento de novas formas de relação e cooperação com os municípios, objetivando maior integração do ensino público municipal e estadual; criação e fortalecimento das comissões municipais e regionais de educação garantindo em suas estruturas a participação das entidades de classe, dos profissionais de educação, dos alunos e representantes da comunidade; democratização do processo de escolha das lideranças escolares (MINAS GERAIS, 1984a, p. 27).

A estratégia de descentralização, proposta no Plano, pressupõe, portanto, em suas linhas gerais, a reorganização administrativa do sistema de educação segundo a descentralização, democratização e participação.

Tais propostas foram implementadas parcialmente, pois a reforma foi limitada pela ação de setores clientelistas, cujos interesses dependiam da instrumentalização da educação visando a fins políticoeleitorais imediatos. Apesar disso, a descentralização do sistema avançou em aspectos importantes, como, por exemplo, maior 
autonomia para escolas e adoção da sua gestão participativa, através da implantação dos Colegiados escolares. No entanto, a reivindicada eleição de diretores não foi adotada formalmente, por pressão desses setores clientelistas que compunham, em grande medida, a base legislativa do governo. ${ }^{7}$

Nesse processo de se repensar o desenho das instituições educacionais brasileiras, os intelectuais exerceram um importante papel, seja pela incorporação de suas ideias pelos atores sociais e políticos, seja pela sua atuação direta na defesa de determinadas políticas (policy advocacy). Especificamente, em Minas Gerais, para se entender a gênese da experiência de reforma do sistema educacional, a partir de 1983, é necessário retomar o debate de ideias no qual estavam envolvidos os intelectuais e os demais setores sociais ligados à área de educação.

A década de 80 iniciou-se envolvida em um debate entre duas concepções de educação contrapostas, que evidenciavam uma disputa entre as ideias que orientaram as políticas educacionais no regime autoritário e as ideias de democratização que, alternativamente, buscavam se afirmar. Por um lado, havia a visão de que a educação deveria enfatizar a formação técnica dos alunos, preparando-os para o mercado de trabalho e de que a função do professor seria a de transmitir um conhecimento pronto e acabado, com 0 objetivo de inserir o aluno numa ordem social já dada, sobre a qual não caberiam maiores questionamentos. Nessa perspectiva, a educação escolar aparecia como funcional aos requisitos da lógica econômica. Por outro lado, grupos à esquerda contrapunham a essa concepção dos anos de 1970 a ideia da educação como meio de formação do homem para a cidadania, através do desenvolvimento de sua consciência critica. A função da educação, nesse sentido, além de seus objetivos técnicos, deveria incorporar uma dimensão social e política, o que exigia, necessariamente, a quebra do padrão vigente até então de centralização do poder, de exclusão da participação da população nas decisões públicas e do uso clientelista dos recursos educacionais. Foi no contexto desse debate que a reforma da educação do governo do PMDB se inseriu, envolvendo uma rede de atores que buscavam repensar as bases nas quais se assentava o sistema educacional.

Como se disse, a reforma teve como momento crucial a posse de um grupo de esquerda na direção da SEE. 0 principal mentor das ações implementadas pela SEE, Neidson Rodrigues, desenvolveu toda sua trajetória intelectual e de militância politica no movimento de reação à concepção de educação adotada pelo regime militar. Intelectual e professor universitário, com vários trabalhos publicados sobre temas educacionais, Neidson Rodrigues ocupou, no governo do PMDB, o cargo estratégico de superintendente educacional da SEE, tendo sido o formulador da política educacional do governo. Sua posição pessoal é representativa de um grupo de intelectuais progressistas que pensavam a educação no periodo. Tomemos algu-

7 A prerrogativa da indicação dos diretores das escolas era, na prática, do político governista mais votado na região em que a escola estava situada. Sobre a implementação da reforma, ver Rocha (2006). 
mas de suas reflexões, que são bastante representativas das ideias que orientaram a reforma da educação nos anos de 1980, no Brasil.

Em um discurso proferido em 1981 e, posteriormente, publicado com o título de "Desafios aos Educadores", podemos encontrar as premissas da atuação de Neidson Rodrigues na SEE. Inicialmente, o autor reforça a importância de se criticar a escola de então:

a crítica radical da escola no Brasil tem procurado desmascarar os vínculos entre a educação e as estruturas econômicas, políticas e sociais. A denúncia da utilização da escola como instrumento de manutenção das relações sociais existentes e veiculação de ideologias manipuladas pelos setores mais privilegiados da sociedade é importante e necessária. É mesmo indispensável para que os educadores e o público em geral percam a ingenuidade de encarar a escola como uma instituição inocente, pairando acima do bem e do mal (RODRIGUES, 1995, p. 71).

Partindo dessa constatação inicial, ele propõe fazer da escola um instrumento de emancipação dos trabalhadores: educar, nesse sentido, implica em fornecer as condições para sua participação consciente nos embates políticos, forma de instaurar uma nova ordem social compativel com os seus próprios interesses. A escola passa, assim, a ter o dever de dar "aos filhos dos trabalhadores condições intelectuais e sociais para que eles possam construir um espírito de solidariedade e de autodesenvolvimento, e não se limitar a reproduzir o saber sabido" (RODRIGUES, 1995, p. 81). Neidson Rodrigues (1995) critica a concepção da educação vista com o objetivo de preparação dos alunos para o mercado de trabalho. Para ele, a educação deveria ser tratada como meio de construção do social, como uma dimensão política dos homens, e não com o objetivo principal de levar os alunos ao mercado de consumo.

Essas ideias eram expressão de um amplo movimento de intelectuais e ativistas da área educacional, do qual ele era um participante destacado. A perspectiva analítica que orientava esses professores de esquerda era inspirada, em grande medida, na obra do pensador italiano Antonio Gramsci, que dá grande relevo à educação e ao papel dos intelectuais nas mudanças sociais. Com o seu conceito de hegemonia, o autor italiano dá ênfase à importância da mudança de consciência das pessoas como passo importante para a transformação social. A hegemonia de uma classe política, para o autor italiano, significa a capacidade desta de persuadir as demais classes sociais a aceitar os seus valores morais, políticos e culturais. Nesse aspecto, 0 papel dos intelectuais é fundamental, pois a conquista e a manutenção da hegemonia é uma questão de educação. Como escreveu Gramsci (apud JOLL, 1977, p. 78), "toda relação de 'hegemonia' é necessariamente uma relação pedagógica". 
A educação torna-se, nesse registro, um espaço fundamental de disputa de poder e, potencialmente, de difusão de mudanças sociais. Diferentemente da visão marxista ortodoxa que considera a revolução, e o fim da propriedade privada, como a forma primeira de transformação da realidade, para os setores de esquerda ligados à educação, o conceito de hegemonia cultural ganhou ênfase como instrumento político de emancipação das classes dominadas. Os intelectuais, nesse sentido, relacionando-se "organicamente" com as massas, são investidos de um sentido de missão como difusores da nova cultura transformadora, base de uma nova sociedade. Portanto, num momento de grande mobilização política pelo qual passava 0 Brasil, discutir o sistema público de educação, a partir das ideias de Gramsci (apud JOLL, 1977), tinha implicações políticas de grande alcance.

Essas ideias, de alguma forma, orientaram a mobilização de uma rede de atores que compartilhavam princípios normativos, diagnóstico e formas de solucionar os problemas da área educacional, constituindo uma comunidade epistêmica (HAAS, 1992 , p. 3). Esse consenso foi cristalizado em instituições diversas como sindicatos de profissionais do ensino, centros de pesquisa, fóruns de debates e associações de pesquisadores. Organizações com fins científicos passaram a se relacionar com associações de representação de interesses, estabelecendo espaços de discussão e difusão de ideias e de formação de novos quadros de militância intelectual e política.

Um marco importante desse processo de institucionalização foi a criação, em 1977, do curso de doutorado em educação na Pontifícia Universidade Católica de São Paulo (PUC-SP), sob a coordenação do professor Demerval Saviani, e com a participação de outros intelectuais comprometidos com a difusão das ideias de transformação da área de educação no Brasil, como Neidson Rodrigues, Carlos Roberto Jamil Curi, Guiomar Namo de Mello e Luis Antônio Cunha. A atuação desse grupo oriundo do doutorado da PUC-SP teve desdobramentos relevantes para a modificação da orientação de diversos cursos no país, dentre eles a reforma do curso de pós-graduação em educação da Universidade Federal de Minas Gerais (UFMG), no início dos anos 80. Com a participação do próprio Neidson Rodrigues, o mestrado em educação da UFMG mudou sua orientação até então tradicional, inovando em relação à maioria dos cursos existentes no Brasil, no sentido de valorizar a experiência prática dos mestrandos em projetos sociais como dimensão relevante da produção intelectual. Passou-se a enfatizar a experiência coletiva de alunos e professores, articulando reflexão e ação como complementares no projeto de transformação social.

Os vários centros de pós-graduação em educação, surgidos nesse período, criaram em 1978 a Associação Nacional de Pesquisa e Pós-Graduação em Educação (ANPEd), com o objetivo de divulgar a produção de conhecimento na área educacional, através, entre outros meios, da realização de reuniões periódicas de pesquisadores. Foi criado também o Centro de Estudos Educação e Sociedade - Cedes e a Associação Nacional 
de Educação (ANDE), destinados a congregar educadores de todo o país para pensar a educação e propor alternativas para a reforma do sistema educacional nacional. Essas duas últimas entidades passaram a editar revistas importantes para a difusão das ideias gestadas. Também, foram organizadas, pelo mesmo grupo, as Conferências Brasileiras de Educação (CBE), voltadas para a produção, discussão e divulgação de diagnósticos, análises, críticas e elaboração de propostas para a implementação de um ensino público democrático e de qualidade. A temática dos seis encontros realizados nos anos de 1980, 1982, 1984, 1986, 1988, 1991, revela bem as preocupações de seus organizadores. Respectivamente, foram intitulados: A política educacional; Educação: perspectiva na democratização da sociedade; Da crítica às propostas de ação; A educação e a Constituinte; A Lei de Diretrizes e Bases da Educação Nacional; Política Nacional de Educação. Tais discussões acabaram pautando programas de candidatos oposicionistas e orientaram a elaboração do capitulo de educação da Constituição Federal (BRASIL, 1988), marco fundamental da democratização política do Brasil. Enfim, a produção acadêmica que tratou da reforma da educação é extensa, tendo sido divulgada através de cerca de 60 revistas especializadas surgidas no período, além de uma grande quantidade de livros publicados.

Ao mesmo tempo, várias associações de caráter reivindicativo dos trabalhadores no ensino iam sendo criadas em todo o Brasil, substituindo entidades conservadoras, de caráter assistencial e atreladas ao governo. Tais associações passavam, em grande medida, a defender as alternativas propostas pelos intelectuais de esquerda para os problemas da educação. Em Minas Gerais, de um lado, havia a Associação dos Professores Públicos de Minas Gerais (APPMG), criada em 1931, e que, na prática, era uma entidade de caráter mais assistencialista que representativo dos interesses da categoria. Em 1979, um grupo de profissionais do ensino público mineiro questionou a representatividade da APPMG, deflagrou uma greve contra sua orientação, que acabou resultando na formação da União dos Trabalhadores do Ensino (UTE). Essa entidade demonstrou grande capacidade de mobilização da categoria, e priorizou, em suas reivindicações, a necessidade de reformas democratizantes do sistema público estadual de ensino.

Na medida em que políticos de oposição começaram a ocupar a chefia de executivos, primeiro municipais e, depois do restabelecimento das eleições diretas para governadores em 1982, também estaduais, as ideias gestadas por essa rede de atores começaram a ser implementadas ${ }^{8}$. Foi assim que os primeiros modelos de administração pública democrática foram adotados em municípios governados por políticos progressistas, como Boa Esperança (ES), Lages (SC) e Piracicaba (SP). Nos estados, experiências pioneiras foram implementadas em Minas Gerais, São Paulo, Rio de Janeiro e Paraná (SAVIANI, 1995, p. 55). Na verdade, com o processo de

80 regime militar suprimiu eleições para os governos estaduais e para municípios considerados estratégicos. No entanto, ao longo de todo período autoritário os prefeitos continuaram sendo eleitos pelo voto popular. 
alternância de poder estatal, os participantes do movimento de renovação da educação passaram a ocupar cargos no aparelho de estado. Muitos foram chamados para compor as equipes das secretarias de educação de estados e municípios governados pela oposição, tendo, assim, a oportunidade de concretizar suas ideias em políticas governamentais. Em Minas Gerais, por exemplo, chegando ao governo, 0 grupo de Neidson Rodrigues adotou a gestão colegiada nas escolas, tendo como fonte de inspiração as Comissões de Fábrica organizadas na Itália por volta dos anos vinte deste século, especialmente na cidade de Turim, e teorizadas por Gramsci (comunicação verbal). ${ }^{9}$

Enfim, este período deixou lições que foram retomadas depois do interregno centralizador e clientelista de 1987-1990, ${ }^{10}$ mais especificamente na Reforma Educacional de 1991, como veremos posteriormente. 0 ambiente de intenso debate e renovação das ideias sobre as questões educacionais e a participação de intelectuais com militância politica em governos reformistas produziram transformações notáveis nos sistemas públicos educacionais do Brasil e, especialmente, de Minas Gerais. Para os protagonistas desse período, como vimos, os objetivos de descentralização e participação se sustentavam em um discurso extremamente politizado.

\section{A reforma no contexto da globalização}

A reforma de 1991, que teve como ponto de partida a eleição de Hélio Garcia para governador do estado de Minas Gerais, pelo Partido das Reformas Sociais (PRS), enfatizava problemas que se conectam com outro plano de eventos. 0 grupo de pessoas que passou a dirigir o sistema estadual de educação estabeleceu sua agenda em referência aos efeitos do processo de globalização, especialmente na esfera da produção e da educação. Foi um processo que se sobrepôs aos objetivos de democratização política que organizaram a agenda dos reformadores do governo Tancredo Neves.

Pode-se demarcar como o momento de inflexão do processo de globalização a metade da década de 1970, quando a ordem mundial entrou em crise, depois de um ciclo de desenvolvimento que Hobsbawm (1995) chamou de "a era de ouro do capitalismo". Como resultado de uma série de fatores, como a crise econômica mundial, a transferência de tecnologia bélica desenvolvida no contexto da Guerra Fria para outros ramos de produção, o colapso dos regimes do "socialismo burocrático", e a hegemonia neoliberal como modelo orientador da ação de uma ampla gama de go-

9 Tal informação foi fornecida por Rodrigues em entrevista ao autor deste trabalho.

10 Em 1986 foi eleito como governador Governo Newton Cardoso, que imprimiu na área da educação um rumo totalmente diverso da política educacional do governo anterior. Sua política contrariou as reivindicações das entidades representativas dos trabalhadores do ensino e as ideias que prevaleceram no período anterior. Esses setores passaram a confrontar o governo. Seu governo pode ser caracterizado por uma ênfase dominante no clientelismo, sem qualquer projeto de maior prazo na gestão da SEE. 0 governador centralizou o poder de tomar decisões em suas mãos e nas de uns poucos assessores, retirando autonomia das secretarias de estado. A gestão do sistema público de educação passou a objetivar primordialmente atrair apoios políticoeleitorais para o grupo no poder. 
vernos, uma nova ordem passou a se configurar no mundo. Esse processo de mudança é denominado amplamente como o fenômeno da globalização. Giddens (1991, p. 69) define globalização como a "intensificação das relações sociais em escala mundial, que ligam localidades distantes de tal maneira que acontecimentos locais são modelados por eventos ocorrendo a muitas milhas de distância e vice-versa". Sem querer apresentar aqui as diversas concepções sobre os significados e as características da globalização, permeadas por interpretações variadas, para os objetivos deste trabalho é suficiente apontar alguns de seus aspectos constitutivos.

Em sua dimensão econômica, a globalização implica a exigência de um novo padrão de produção como requisito para a concorrência das economias no mercado mundial. A nova organização da produção busca, com cada vez mais ênfase, o aumento da produtividade, da qualidade e da redução dos custos dos produtos, passando a demandar, para tal, um novo tipo de trabalhador. A experiência japonesa, em particular, com o chamado Toyotismo, fornece um novo padrão de organização da produção que se torna paradigma para a maioria dos paises a partir dos anos de 1980. Nele o administrador de uma empresa tem seu papel ampliado: deve se preocupar com o mercado, com a melhora do processo de produção e com o desenvolvimento de novos produtos. A autonomia do trabalhador no processo de trabalho cresce enormemente. A gerência da empresa passa a ser participativa, visando a aproveitar o conhecimento de quem nela trabalha, com o objetivo de aumentar a produtividade e a qualidade dos produtos, de melhorar os processos produtivos e de reduzir os custos. Nesse sentido, com o aumento do poder de decisão dos trabalhadores sobre o processo de produção, os niveis hierárquicos dentro de uma empresa são reduzidos, bem como os postos de trabalho. Segundo Sennett (1999, p. 60), na era do que ele chamou de capitalismo flexivel, a "forma de produção exige rápidas tomadas de decisões, e assim serve ao grupo de trabalho pequeno; numa grande pirâmide burocrática, em contraste, a tomada de decisões perde rapidez". Ou seja, para competir, as empresas necessitam de agilidade na tomada de decisões, o que exige novas formas de organização e gerenciamento.

Todas essas transformações são vistas pelos setores empresariais e pelos formuladores de políticas públicas como cruciais para a sobrevivência das empresas. Especialmente no caso brasileiro, com o acirramento da competitividade de amplos setores da economia devido à abertura do mercado brasileiro para produtos estrangeiros no início dos anos de 1990, fruto da adequação da política governamental aos princípios neoliberais, a difusão do Toyotismo é vista como imperativo para responder às exigências do novo contexto (FERRO, 1993, p. 22). Como referido acima, a competitividade econômica passa a depender do incremento tecnológico e da crescente qualificação do trabalhador. Nesse sentido, a educação passa a ser vista como fator fundamental de desenvolvimento econômico. Como é interessante observar, a avaliação dos empresários nacionais sobre o principal obstáculo para a introdução do novo modelo, no Brasil, seria o baixo nivel educacional e de qualificação do trabalhador brasileiro (MATOSO, 1993, p. 21). 
Com a posse do governo Hélio Garcia, as transformações e o diagnóstico relatados acima passaram a emoldurar as ações na área educacional. 0 novo governador era um político de tradição conservadora e de métodos clientelistas, mas também de muita sagacidade política. Ele assumiu o governo com consciência das pressões por mudanças de ordem políticoadministrativa e, sem se desvincular das velhas práticas, agiu no sentido de, a seu modo, levar a cabo algumas reformas. Buscou compatibilizar, em seu governo, interesses clientelistas com as reivindicações de democratização da sociedade civil. No caso da educação, no entanto, priorizou a reforma do sistema pelos motivos relacionados com a necessidade de fornecer as bases necessárias para o desenvolvimento econômico no novo contexto internacional. Com esse objetivo, o governador indicou para secretário da educação Mares Guia Neto, empresário da área de ensino sem experiência anterior em política partidária. 0 novo secretário pode ser classificado como componente de uma "elite desenvolvimentista"11.

Mares Guia Neto assumiu a direção da SEE, herdando os resultados institucionais já alcançados pelo amplo movimento que participou das reformas dos sistemas educacionais no período anterior. As bases da descentralização e participação estavam lançadas pelas reformas consolidadas no governo de Tancredo Neves, e pelos parâmetros de organização do sistema educacional estabelecidos pela Constituição Federal (BRASIL, 1988) e pela Constituição Estadual de 1989 (MINAS GERAIS, 2003)'12. Dessa forma, se por um lado Mares Guia Neto já encontrou um caminho trilhado de reformas, ainda que incompleto, por outro lado defrontou-se com os efeitos do interregno centralizador e clientelista de 1987-1990, cujas consequências deletérias, repudiadas por amplos setores sociais, apenas reforçaram os objetivos de descentralização e participação.

Reiterando o argumento central dos grupos reformistas anteriores, cristalizado nas constituições federal e estadual, o novo governo diagnosticou a impossibilidade de se administrar de forma centralizada um sistema educacional das dimensões do de Minas Gerais, enfatizou a necessidade de se contemplar as realidades regionais, de combater a repetência e a evasão escolar e de extirpar as práticas clientelistas de utilização políticoeleitoral das escolas. Assim cinco prioridades foram definidas pela direção da SEE, quais sejam: 1. autonomia da escola nos aspectos financeiro, pedagógico e administrativo; 2 . fortalecimento da direção da escola através da liderança da diretora e do Colegiado; 3. programa de aperfeiçoamento e capacitação, com o trei-

11 Essa qualificação diz respeito ao protagonismo que membros da elite econômica tiveram em diversas reformas com o objetivo de fornecer condições necessárias de modernização da economia e reprodução do capital, em contraste com as elites econômicas tradicionais, relacionadas com formas pré-capitalistas ou formas mais atrasadas de produção. Tiveram relevância em diversas reformas brasileiras. Ver especialmente o caso abordado em Tendler (1999).

12 Tanto a Constituição Federal (BRASIL, 1988), como a Constituição Estadual DE 1989 (MINAS GERAIS, 2003), contemplam os princípios de descentralização e participação, em geral, e especificamente para a área da educação pública. 
namento de professores, especialistas e funcionários; 4. avaliação sistemática do funcionamento do sistema; e 5 . integração da rede estadual com as redes municipais.

Como fica claro, essa lista de prioridades replica no essencial a agenda dos setores reformistas que atuaram no período reformista do governo Tancredo Neves. Porém, apesar desse elemento "continuísta", fundado nos objetivos de descentralização e participação, a reforma sustentou-se a partir de uma outra referência argumentativa, animada por problemas originados do processo de globalização descritos anteriormente. Se o contexto que marcou as mudanças na educação na primeira metade da década de 1980 foi o movimento pela democratização política brasileira, a Reforma Educacional de 1991 se explica, em grande medida, em referência às transformações pelas quais passara o mundo, no último quartel do século $X X$, e que impactou a definição da agenda pública brasileira nos primeiros anos de 1990.

0 ponto a ressaltar é que no programa de governo da campanha eleitoral vitoriosa de Hélio Garcia (1990, p. 1) já estava explícita a preocupação de

enfrentar o duplo desafio de reverter, com urgência, o quadro social dramático em que se encontra a população mineira e, ao mesmo tempo, preparar Minas para uma posição de liderança no século XXI, sintonizada com as profundas transformações econômicas, tecnológicas e sociais em curso no pais e no mundo [...].

Traduzindo essa preocupação para a questão educacional, a nova equipe de governo estabelecia, com maior ênfase, a necessidade de sintonizar a sua política educacional com a nova ordem internacional, com a globalização dos mercados e com as novas formas de organização do trabalho.

Direcionando um olhar retrospectivo para o processo de reforma, podemos constatar que para os dirigentes da SEE, do período 1983-1986, qualidade na educação significava formação de cidadania política para construção de uma sociedade democrática, em seu sentido formal de liberdade, mas também no seu sentido substantivo de uma distribuição mais igualitária de riqueza e oportunidades. Já para os responsáveis pela reforma de 1991, a ideia de qualidade passa a relacionar educação, tecnologia e desenvolvimento econômico, no contexto do mundo globalizado. A educação passava a ser considerada segundo os imperativos da lógica do desenvolvimento econômico, expressando uma preocupação central das chamadas "elites desenvolvimentistas".

Nesse sentido, Mares Guia Neto (1991) constata que

a qualidade do serviço prestado na educação está comprometida. A comprovação mais significativa desta realidade é a 
insatisfação da sociedade com o ensino que lhe oferecemos, pois a sociedade está se conscientizando do real papel da educação no desenvolvimento social e econômico do País.

Essa mudança dos argumentos, que acompanhou a reforma educacional, fica ainda mais patente nas palavras de Mares Guia Neto (1993), proferidas sintomaticamente no I Congresso Brasileiro de Financiamento do Desenvolvimento. Em contraste com o discurso anterior, o argumento central desenvolvido pelo dirigente da SEE enfatizava que 0 desenvolvimento brasileiro baseado em mão de obra desqualificada e barata havia se esgotado no início da década de 1980 . Ele constou que as empresas passaram a se mover pelo mundo em busca de competência técnica, pois as novas tecnologias de produção assim o exigiam. Dessa forma, a qualidade da mão de obra e, portanto, seu nivel educacional, tornava-se requisito para o desenvolvimento econômico. Mares Guia Neto (1993) buscou sustentar seus argumentos com o exemplo do sucesso econômico dos "tigres asiáticos", em grande medida, segundo diversos analistas, pela prioridade dada à educação. Nessa linha, Mares Guia Neto $(1993$, p. 5) afirmava que

0 Professor de Yale Paul Kennedy, autor de Preparando-se para o Século 21 - Perdedores e Ganhadores, afirma que a principal razão para o rápido desenvolvimento dos países asiáticos é a sua ênfase na educação. Kennedy relaciona os latino-americanos, inclusive o Brasil, entre os prováveis perdedores na luta pelo desenvolvimento.

Diante deste quadro, há especialistas que defendem o ponto de vista de que o Brasil estaria hoje em melhores condições sociais e econômicas se a ênfase dos planos governamentais das décadas de 1960 e 1970 tivesse sido a educação do povo brasileiro ao invés da industrialização do país.

No mesmo sentido, o consultor da SEE e diretor da Divisão de Política de Formação Profissional da Organização Internacional do Trabalho, Cláudio de Moura Castro $(1994$, p. 15), afirmou que

os países que cuidam bem da sua educação são justamente aqueles que estão tendo sucesso econômico. Isto é ainda mais verdadeiro hoje com a adoção crescente de formas de organização complexas e novas tecnologias de produção. Países como o Brasil, que iam razoavelmente bem apesar do seu fraco desempenho educativo, não parecem ter hoje as mesmas chances de êxito.

E ainda que,

chegamos ao limite do que se pode fazer com um grupelho bem educado liderando uma força de trabalho educacio- 
nalmente capenga. Queremos o desenvolvimento econômico. Deitamos olho gordo nos êxitos recentes de países como Coréia e Cingapura, mas não queremos ver o que se passa atrás do palco. Fazemos vista grossa para o esforço diuturno de manter boas escolas (CASTR0, 1994, p. 21).

Justificando o risco da redundância, é interessante ressaltar aqui a reiterada referência aos "tigres asiáticos" por parte dos mentores da Reforma Educacional de 1991. Para eles, desenvolver um ensino básico de qualidade e universalizado passa ser imperativo para os demais paises que almejam se desenvolver, como demonstrou a experiência daqueles paises orientais.

No entanto, se mudou a concepção sobre o papel da educação e se modificaram os argumentos sobre a necessidade de transformação do sistema público de educação, como tentamos demonstrar, permaneceu o conteúdo da reforma que estava na agenda desde o final dos anos de 1970. Também para os reformadores de 1991, a centralização excessiva do sistema e seu uso para fins políticoeleitorais explicavam o insatisfatório funcionamento do setor. Ao avesso, a solução estaria na descentralização, democratização e autonomia de gestão das escolas, com envolvimento comunitário traduzido em participação e responsabilização de toda a comunidade escolar pelo seu bom funcionamento.

A produção dessas ideias envolveu uma rede de pessoas e instituições, formando o que foi designado como uma comunidade epistêmica, já que especialistas na área da educação passaram a difundir, de forma relativamente coordenada, um conjunto de argumentos teoricamente articulados para a reconfiguração dos sistemas educacionais. Nesse sentido, para o caso de Minas Gerais, podemos classificar dois grupos que são importantes no desenvolvimento da reforma. Em primeiro lugar, Mares Guia Neto indicou para os postos de direção estratégicos da SEE funcionários de carreira da secretaria que haviam atuado na reforma dos anos de 1980 e que, portanto, agregavam uma considerável experiência na implementação das ações de descentralização e participação, desde então adotadas. Esse grupo de burocratas, que vinha sendo formado desde o final dos anos de 1970 no interior da máquina governamental - e aos quais fizemos referência no tópico anterior deste trabalho , tinha sentido de missão e compromisso com a reforma do sistema educacional, agregado à vivência adquirida ao longo de mais de uma década de trabalho com as políticas de reforma. Ao lado disso, o secretário mobilizou um grupo de consultores especializados na área de politicas educacionais, intelectuais experientes e vinculados ao Banco Mundial. 0 interessante é que, em ambos os casos, essas pessoas, de alguma maneira, haviam compartilhado das ideias e participado do movimento de reforma dos anos de 1980.

Tomemos, como exemplo, o caso de Guiomar Namo de Mello, consultora do Banco Mundial para a Reforma de 1991 em Minas Gerais. Sua trajetória pessoal é exemplo da mudança de enfoque na abordagem da política educacional em relação 
ao período anterior. Mello (apud MATTOS, 1998), que participou do grupo que no início dos anos de 1980 professava um discurso fortemente politizado para abordar o problema da educação ${ }^{13}$, passou nos anos de 1990, a compartilhar das ideias divulgadas pelo Banco Mundial. Segundo ela, em sua nova ênfase que relaciona educação e economia,

os países industrializados mais adiantados deslocam [...] as prioridades de investimento em infra-estrutura e equipamentos para a formação de habilidades cognitivas e competências sociais da população. Esse deslocamento faz com que a educação escolar adquira centralidade nas pautas governamentais e na agenda dos debates que buscam caminhos para uma reestruturação competitiva da economia, com eqüidade social (MELLO apud MATTOS, 1998, p. 120).

Nessa mesma linha de pensamento, João Batista de Oliveira, também consultor do Banco Mundial e principal assessor de Mares Guia Neto na SEE, afirma que o Estado deveria cumprir o papel não de "fazedor" da educação, mas sim de regulador, passando para a comunidade escolar a responsabilidade de gestão das escolas. Segundo Oliveira (apud MATTOS, 1998, p. 121), no final do século XX esgotou-se "a ideia de que a escola possa ser gerenciada como um serviço público, muito menos de massa".

Podemos afirmar que, de forma geral, a chamada Reforma Gerencial fornecia o conjunto de ideias que passa a orientar a reforma do sistema público de educação mineiro, cujos princípios são difundidos principalmente por consultores do Banco Mundial. Componente privilegiado desse modelo gerencial, os programas de Qualidade Total passam a ser adotados em todo mundo. Em 1990, surgem as primeiras tentativas de implantar programas de Qualidade Total na administração pública brasileira. É nesse ano, por exemplo, que é instituído, pelo Governo Federal, o Prêmio Nacional de Qualidade e o Programa Brasileiro de Qualidade e Produtividade. Seguindo a orientação de seus consultores, em setembro de 1991, Mares Guia Neto iniciou um projeto de parceria entre a SEE e a Fundação Christiano Ottoni, uma das maiores especialistas de programas de qualidade no pais, com financiamento do Banco Mundial, visando implantar a gestão por Qualidade Total no sistema público estadual de educação (BARBOSA, 1995).

A adaptação dos princípios da gerência de Qualidade Total para a educação pode ser exemplificada com as ideias contidas em dois livros de Ramos (1994; 1995), que em 1992 trabalhava no Núcleo Central de Qualidade e Produtividade do Ministério da Educação. A autora enfatiza, inicialmente, a importância do trabalho em equipe, visando a quebrar "as barreiras entre os escalões hierárquicos e as paredes que separam

13 Mello participou do grupo de universitários que buscou difundir novas ideias na área de educação, conforme foi relatado anteriormente. 
as pessoas" (RAMOS, 1994, p. 11). 0 foco das organizações, segundo ela, deveria ser 0 atendimento dos "interesses, desejos e necessidades do cliente". Para tal, seria necessário às organizações "manter em funcionamento um canal de comunicação permanente com aqueles que utilizam os seus serviços". Isto pressuporia "uma relação de parceria estável, com a mobilização e a adesão de toda a comunidade escolar" (RAMOS, 1994, p. 17). Toda a ênfase dos argumentos de Ramos, como de resto da Reforma Gerencial, é técnica, ao considerar como negativa a dimensão política presente nas organizações. Esse desejo de "descontaminar" a gestão das escolas dos seus aspectos políticos fica claro na afirmação de que "a gestão democrática não implica, necessariamente, eleição [de diretores escolares]" (RAMOS, 1995, p. 11).

Se esse discurso tecnicista contrastava com o tom explicitamente político dos reformadores dos anos de 1980, em essência, tais princípios reproduziam sob outra roupagem retórica o modelo de reforma adotado na educação pública mineira na década de 1980: autonomia das escolas com participação da comunidade escolar. Um aspecto dessa autonomia, que denota um tratamento tecnicista baseado nos princípios da administração por Qualidade Total, foi a terminologia utilizada para designar uma nova sistemática de escolha de diretores escolares, acabando com as indicações por critérios político-partidários. ${ }^{14}$ Ao invés de eleição, antiga reivindicação dos movimentos sociais, o governo adotou uma sistemática denominada "apuração de aptidão para a liderança". Exemplo desse espírito, digno de nota, foi a exortação do secretário Marres Guia Neto ao afirmar a necessidade de "realizar, como condição para melhorar a qualidade do nosso ensino básico, um trabalho sério, apolítico, com o engajamento de todos, de valorização da escola pública e do professor de primeiro e segundo graus" (MINAS GERAIS, 1993, p. 13, grifo nosso).

Como deve ter ficado claro acima, com as reiteradas referências da filiação dos consultores da SEE com organismos internacionais, especialmente com o Banco Mundial, a reforma do sistema educacional de Minas Gerais, como de resto de toda a América Latina, encontrou neles um suporte institucional considerável. Essas instituições passaram, como vimos nas palavras de alguns de seus representantes, a enfatizar a necessidade de reforma dos sistemas educacionais, através da estratégia da descentralização e participação. Essas concepções compuseram um receituário aplicado em toda América Latina: reformas baseadas nesses principios foram adotadas no Chile, 1981; na Colômbia, 1989; no México, 1992; e em El Salvador, 1996. Portanto, para explicar a Reforma de 1991 é necessário voltar o olhar para o papel do Banco Mundial como indutor na produção políticas públicas. Esse deslocamento de olhar remete a um processo ainda pouco analisado: a internacionalização da produção de políticas públicas.

$14 \mathrm{Um}$ dos instrumentos mais importantes do uso clientelista das escolas era a indicação de seus diretores por políticos governistas. Esse instrumento foi combatido tanto pelos responsáveis da reforma no governo Tancredo Neves, como pelos responsáveis pela reforma no governo Hélio Garcia. 
Como se sabe, a atuação do Banco Mundial obedece a prioridades definidas pelos Estados Unidos e outros países desenvolvidos como Japão, Alemanha, França e Reino Unido, já que a capacidade de influenciar suas decisões é proporcional ao aporte de capital realizado por cada pais..$^{15}$ Ao longo de sua história, devido a fatores diversos, o Banco Mundial veio modificando as suas prioridades de investimento. 0 Banco inicia sua atuação priorizando o setor de infra-estrutura, para depois de 1968 priorizar o setor agrícola, até chegar a dar ênfase nos setores sociais. A partir do final dos anos de 1980, o Banco Mundial tem dado ênfase especial ao setor educacional. A participação do setor educacional nos empréstimos do Banco Mundial ao Brasil, por exemplo, passou de $2 \%$ do montante total, nos anos de 1987-1990, para 29\%, no periodo 1991-1994 (SOARES, 1998, p. 35). Essa priorização explica-se, especialmente, como fator de adequação da formação de "capital humano" às exigências do novo padrão produtivo instaurado com as novas tecnologias e formas de organização dos empreendimentos econômicos, fornecendo os requisitos para a reprodução do capital.

Como uma estratégia dos organismos internacionais para influenciar as políticas dos países mais pobres, em 1990 agências internacionais de financiamento e auxílio à educação e ao desenvolvimento, como Banco Mundial, UNICEF e UNESCO, realizaram a "Conferência Mundial sobre Educação para Todos", em Jomtien, na Tailândia, que reuniu governos e organizações não governamentais para discutir a educação no mundo. 0 Brasil, participante da conferência, se comprometeu com as teses resultantes do encontro, que vão ser incorporadas no Plano Decenal de Educação para Todos 1993-2003, do Governo Federal. Os pontos enfatizados foram: priorizar o ensino fundamental; a descentralização dos sistemas educacionais; a racionalização dos gastos públicos no setor; e a redução da presença do Estado na oferta dos serviços sociais.

É sintonizado com alguns desses princípios que o Plano Decenal de Educação para Todos em Minas Gerais, divulgado pelo governo mineiro em 1992, foi elaborado. 0 documento afirma "cumprir compromisso público assumido pelo Brasil na Conferência Internacional de Jomtien, Tailândia, em março de 1990" e transpõe a proposta exposta anteriormente: a educação é vista como instrumento de compatibilização entre desenvolvimento e democracia, relacionando o "crescimento econômico à melhoria da qualidade de vida e à consolidação dos valores democráticos" e prioriza a oferta de um ensino fundamental de qualidade para todos, visando resolver o problema da baixa produtividade do trabaIho (apud MATTOS, 1998, p. 111).

15 Refletindo a participação no aporte de capital do Banco, em 1994 os EUA tinham a presidência do Banco e, juntamente com Japão, Alemanha, Reino Unido e França, controlavam quase 40\% dos votos (SOARES, 1998, p. 16). 
Nesse contexto, a partir de meados da década de 1980, iniciam-se negociações entre diversos estados brasileiros e o Banco Mundial para o desenvolvimento de projetos na área educacional. De forma pioneira, em 1992, Minas Gerais estabeleceu negociações com essa agência de financiamento visando carrear recursos para o setor (TOMMASI, 1998, p. 202). Os fatores que foram facilitadores para a concessão de um empréstimo para Minas Gerais, segundo avaliação do próprio Banco Mundial, referem-se às medidas adotadas pela SEE nos dois primeiros anos do Governo Hélio Garcia, obviamente já adequadas aos princípios exigidos pelo Banco (TOMMASI, 1998, p. 207).

A Reforma Educativa de 1991 foi concebida, portanto, num contexto em que diversos atores passaram a considerar a educação como investimento prioritário para o desenvolvimento econômico, com a função de dar sustentação à geração de tecnologia, qualificação da força de trabalho segundo as exigências das novas formas de produção e preparação das pessoas para competirem no mercado. Tais objetivos articulavam-se com interesses internos de desenvolvimento econômico e modernização do setor produtivo nacional, bem representados por um membro da elite econômica como Mares Guia Neto. Articulado com esses interesses, o Banco Mundial deu suporte institucional para o trabalho de uma rede de especialistas na propagação de um corpo de ideias sobre reformas educacionais, fundadas nos princípios, já então prioritários na agenda, de descentralização e participação.

\section{Conclusão}

Neste trabalho, procuramos demonstrar como uma rede de atores articulou ideias sobre como redesenhar as instituições públicas de ensino de Minas Gerais. Durante cerca de duas décadas, sindicatos, universidades, associações de pesquisas, elites empresariais e instituições financeiras internacionais sustentaram a necessidade de se reformar as instituições educacionais. Redes de especialistas da área educacional, conectadas com uma variedade de atores sociais, desenvolveram suas próprias concepções sobre as politicas educacionais.

Nesse processo, as ideias foram elaboradas no contexto do esgotamento de um paradigma anterior de organização do Estado, fundado na centralização decisória, nos critérios burocráticos e, ao mesmo tempo, na instrumentalização das instituições educacionais para fins clientelistas. Nos dois momentos da reforma, os atores foram desafiados a adaptar os seus interesses aos constrangimentos que a experiência com a política passada foi cristalizando ao longo do tempo (policy learning): crescentemente, forjou-se um acordo sobre as consequências nefastas da centralização, burocratização e do clientelismo que caracterizavam o setor. É essa herança negativa que estabeleceu uma base de consenso sobre o conteúdo da reforma entre grupos diferenciados em termos ideológicos e políticos. 
Como procuramos apontar, nos anos 1980, grupos de esquerda, articulados em movimentos sociais e instituições universitárias e de pesquisa formaram uma rede de atores sociais que pressionaram pela realização das reformas. Um grupo desses atores acessou o poder estadual e passou a adotar um primeiro conjunto de ações visando reformar o sistema educacional de Minas Gerais, a partir de ideias fortemente baseadas na análise de classes. 0 grande objetivo era criar as condições de uma sociedade mais democrática e igualitária, utilizando a educação como meio promoção social das classes oprimidas e como forma de difusão dos valores de cidadania e igualdade. Posteriormente, no início dos anos de 1990, consultores de instituições internacionais como o Banco Mundial, expressando interesses do capital, também desenvolveram ideias e definiram ações visando a reformar a educação pública. 0 objetivo principal da educação, nesse segundo momento, era formar adequadamente a mão de obra, segundo as condições impostas, no mundo globalizado, para a reprodução do capital. A educação passou, então, a ter relevância como fator de qualificação do trabalho num mundo em que a concorrência econômica ficou cada vez mais acirrada.

Apesar dessas diferenças de interesses e de enfoque, um grande consenso foi criado entre os dois grupos em torno da importância e do valor da educação, seja como instrumento de desenvolvimento econômico e social, seja como instrumento da formação política e cultural do cidadão. A defesa da educação passou a ser feita tanto pelos adeptos da economia de mercado quanto pelos seus críticos, com ênfases e motivos diferentes, naturalmente. Especialmente, concordavam com os efeitos negativos de um sistema centralizado, burocratizado e utilizado para fins clientelistas. 0 paradigma da descentralização e participação foi assumido, por ambos os grupos, como essencial para a reformulação do sistema ${ }^{16}$.

Assim, comunidades epistêmicas diferenciadas passaram a compartilhar um consenso básico sobre os requisitos da "boa institucionalidade". Esse consenso foi impulsionado, como vimos, por fatores sociais e pelo embate de interesses, contrapondo, de um lado, políticos governistas clientelistas e, de outro lado, movimentos sociais democratizantes e elites desenvolvimentistas. 0 debate alcançou a sociedade, envolvendo políticos, partidos, grupos de interesses e imprensa. A reforma das instituições educacionais foi, em certa medida, fruto dos resultados de embates eleitorais. A importância do papel das ideias na produção das políticas de reforma é clara, na medida em que políticos, burocratas, lideranças diversas e especialistas compartilharam de um objetivo comum, cujo resultado político foi inegável: superar as formas institucionais anteriores, que já não respondiam os desafios colocados pelo contexto, implementando uma nova institucionalidade fundada nos princípios da descentralização e participação.

16 É interessante como Draibe e Henrique (1988, p. 54) notam a "intrigante convergência [...] entre a proposta conservadora de diminuição do papel centralizador e intervencionista do Estado, por um lado, e as sugestões progressistas de descentralização e autonomização das políticas sociais, em direção a formas mais participativas dos beneficiários, por outro". 


\section{Agradecimentos}

Agradeço a Argelina Figueiredo que me orientou em uma pesquisa da qual originou este trabalho. Sou grato também aos comentários valiosos do parecerista anônimo desta revista. Naturalmente que a responsabilidade pelas imprecisões é do autor.

\section{Referências}

ALMEIDA, M. Federalismo e politicas sociais. Revista Brasileira de Ciências Sociais, São Paulo, n. 28, 1995.

BARBOSA, E. Implantação de Qualidade Total na educação. Belo Horizonte: UFMG, 1995.

BRASIL. Constituição (1988). Constituição da República Federativa do Brasil. Brasília, DF: Senado Federal, 1988.

CASTRO, C. de M. Educação brasileira: consertos e remendos. Rio de Janeiro: Rocco, 1994.

DRAIBE, S.; HENRIQUE, W. Welfare State, crise e gestão da crise: um balanço da literatura internacional, Revista Brasileira de Ciências Sociais, São Paulo, v. 3, n. 6, fev. 1988.

FARIA, C. Ideias, conhecimento e políticas públicas: um inventário sucinto das principais vertentes analíticas recentes. Revista Brasileira de Ciências Sociais, São Paulo, v. 18, n. 51, p. 21-30, 2003.

FERRO, J. Toyotismo: adquirindo competitividade. Revista dos Metalúrgicos, São Paulo, ano 1,

n. 1, dez. 1993.

GARCIA, H. Programa de educação para o Governo Hélio Garcia 1991/94. Belo Horizonte: [s. n.], 1990.

GIDDENS, A. As conseqüências da modernidade. São Paulo: Ed. Unesp, 1991.

HAAS, P. Introduction: epistemic communities and international policy coordination. International Organization, v. 46, n. 1, p. 1-35, 1992. 
HALL, P. Policy paradigms, social learning, and the state: the case of economic policymaking in Britain. Comparative Politics, New York, april, v. 25, n. 3, 1993.

HOBSBAWM, E. Era dos extremos: o breve século XX: 1914-1991. São Paulo: Cia. das Letras, 1995.

JOHN, P. Analysing public policy. London: Pinter, 1999.

JOLL, J. As ideias de Gramsci. São Paulo: Cultrix, 1977.

KUHN, T. As estruturas das revoluções científicas. São Paulo: Perspectiva, 1975.

MARES GUIA NETO, W. S. Educação e desenvolvimento. In: CONGRESSO BRASILEIRO DE FINANCIAMENTO DO DESENVOLVIMENTO, 1. 1993, São Paulo. Trabalhos apresentados... São Paulo: Associação de Instituições Financeiras de Desenvolvimento, 1993.

Informativo Pitágoras, Belo Horizonte, ano 1, n. 0, jun. 1991.

MATOSO, J. 0 toyotismo dentro e fora da fábrica. Revista dos Metalúrgicos, São Paulo, ano 1, n. 1, dez. 1993.

MATTOS, L. Democracia e colegiado de escola: qual democracia?. Rio de Janeiro: Ed. da UFRJ, 1998.

MINAS GERAIS. Constituição (1989). Constituição do Estado de Minas Gerais. Recivil, Belo Horizonte, 2003. Disponivel em: <http://www.recivil.com.br>. Acesso em: 4 abr. 2011.

Secretaria de Educação. Plano Mineiro de Educação 1984/1987. Belo Horizonte, 1984a.

$1984 b$.

Proposta de reorganização da escola: ciclo básico. Belo Horizonte,

RAMOS, C. Pedagogia da Qualidade Total. Rio de Janeiro: Qualitymark, 1994. Sala de aula de qualidade total. Rio de Janeiro: Qualitymark, 1995.

ROCHA, C. Política e mudança institucional: a reforma da educação pública de Minas Gerais. In: SOUZA, C.; DANTAS NETO, P. Governo, politicas públicas e elites politicas nos estados brasileiros. Rio de Janeiro: Revan, 2006. 
RODRIGUES, N. Lições do Príncipe e outras lições. São Paulo: Cortez, 1995.

ROSE, R. Lesson-drawin in public policy. New Jersey: Chatham House, 1993.

SABATIER, P.; JENKINS-SMITH. Policy change and learning: an advocacy coalition approach. Boulder, CO: Westview Press, 1993.

SANTOS, W. A trágica condição da política social. In: ABRANCHES, S.; SANTOS, W.; COIMBRA, M. Política social e combate à pobreza. Rio de Janeiro: Jorge Zahar, 1987.

SAVIANI, D. Os ganhos da década perdida. Presença Pedagógica, São Paulo, n. 6, nov./dez., 1995.

SENNET, R. A corrosão do caráter. Rio de Janeiro: Record, 1999.

SOARES, M. C. C. Banco Mundial: políticas e reformas. In: TOMMASI, L. O Banco Mundial e as políticas educacionais. São Paulo: Cortez, 1998.

TENDLER, J. Mitos da reforma do Estado e a descentralização: conclusões de um estudo de caso no Brasil. In: MELO, M. Reforma do Estado e mudança institucional no Brasil. Recife: Massangana, 1999.

TOMMASI, L. Financiamentos do Banco Mundial no setor educacional brasileiro: os projetos em fase de implantação. In: . O Banco Mundial e as políticas educacionais. São Paulo: Cortez, 1998.

Recebido em: 25/08/2009

Aceito para publicação em: 21/10/2010 